\title{
Sequential Injection Analysis-Based System for On-Line Monitoring of Nitrite and Nitrate in Wastewaters
}

\author{
Rui A. S. LaPa, ${ }^{\dagger}$ José L. F. C. Lima, and Ivone V. O. S. Pinto \\ CEQUP/Departamento de Química-Física, Faculdade de Farmácia da Universidade do Porto, \\ R. Aníbal Cunha, 164, 4050-047 Porto, Portugal
}

\begin{abstract}
A sequential injection analysis system has been developed for on-line monitoring of nitrite and nitrate in wastewaters, based on the Griess-Llosvay reaction and spectrophotometrical measuring of the absorbance at $543 \mathrm{~nm}$. Nitrate is previously reduced to nitrite in a copperized cadmium column and analyzed as nitrite. The proposed system is fully automatized and is able to monitor nitrite and nitrate, simultaneously, in samples at a frequency of about 24 samples per hour with a relative standard deviation (RSD) better than $2.0 \%$ for nitrite and $1.3 \%$ for nitrate. The calibration graph was linear between $0.05-25 \mathrm{mg} \mathrm{dm}^{-3}$ for nitrite and $0.05-15 \mathrm{mg} \mathrm{dm}^{-3}$ for nitrate.
\end{abstract}

(Received June 6, 2000; Accepted August 11, 2000)

\section{Introduction}

The rapid growth of biotechnological research in the last years has emphasized the demand for simple and robust analytical techniques applicable to bioprocess monitoring. On-line determination of certain chemical species in bioprocesses is of significance with regard to controlling a process more efficiently, for reasons of economy, environmental quality and product quality. ${ }^{1}$

Automatic systems for on-line process control based on flow analyses were developed and used in the monitorization of chemical species in natural waters and industrial effluents. More robust systems with simple operation and a minimum of maintenance are therefore needed in order to advance the routine application to the industrial processes. The sequential injection analysis (SIA) comprising only a single propulsor system, single valve and a single channel, has been conceived and found to overcome the difficulties related to the conventional flow systems, such as, manual reconfiguration of the flow channel, high reagent consumption due to the continuous flow operation and frequent recalibration of the system. Routine application of the conventional flow systems for bioprocess monitoring is largely restricted to research laboratories, as the robustness and ease of operation are not sufficiently good for process control..$^{2-7}$

Nitrite and nitrate are chemical species in waters that need monitoring, due to their known toxicity to animal and human metabolism, especially when children are concerned. Nitrate is related with methaemoglobinaemia (Blue Baby Syndrome) and there is a possible relation with stomach cancer and hypertension. ${ }^{8-12}$

The nitrogen content, as nitrite and nitrate, of lakes, rivers and streams usually arises from the groundwater, sewerage effluent or drainage and leaching from agricultural land. ${ }^{13}$ The last is the

\footnotetext{
† To whom correspondence should be addressed.

E-mail: laparuas@mail.ff.up.pt
}

most significant input and nitrate levels have increased substantially because of the increased use of nitrogen-based fertilisers. ${ }^{13-15}$

Several methods are available for the nitrite and nitrate determination in waters, ${ }^{15-17}$ including direct ultraviolet spectrophotometry, derivatization with sulfosalicylic acid, use of a nitrate-selective electrode and reduction to nitrite followed by derivatization, e.g., with $N$-(1-naphtyl)ethylenediamine dihydrochloride (N1NED) and sulfanilamide.

In this paper, the design of a fully automated and robust system based on SIA, allowing the simultaneous monitoring of nitrite and nitrate in wastewaters, is described. The nitrite determination is based on the Griess-Llosvay reaction: nitrite in the presence of sulfanilamide and N1NED produces, by diazotization and coupling reaction, a colored compound that can be spectrophotometrically detected at $543 \mathrm{~nm}$. Nitrate is determined after reduction to nitrite in a copperized cadmium column. ${ }^{18}$

The parameters that affect this determination were evaluated. The working characteristics of this system are rapid, sensitive and accurate, and applicable to the monitorization of nitrite and nitrate levels in wastewaters.

\section{Experimental}

\section{Reagents and solutions}

Solutions were prepared using high purity water, with conductivity less than $0.1 \mu \mathrm{S} \mathrm{cm} \mathrm{cm}^{-1}$. Analytical grade reagents were used throughout.

A nitrite stock solution $\left(1 \mathrm{~g} \mathrm{dm}^{-3}\right)$ was prepared from sodium nitrite $\left(4.93 \mathrm{~g}\right.$, dried for $2 \mathrm{~h}$ at $\left.105-110^{\circ} \mathrm{C}\right)$ in water. A nitrate stock solution $\left(1 \mathrm{~g} \mathrm{dm}^{-3}\right)$ was prepared from potassium nitrate $\left(7.22 \mathrm{~g}\right.$, dried for $2 \mathrm{~h}$ at $\left.105-110^{\circ} \mathrm{C}\right)$ in water. Working standards were daily prepared by appropriate dilution of each stock solution with water.

The chromogenic reagent was prepared by dissolving $10 \mathrm{~g}$ of sulfanilamide and $1 \mathrm{~g}$ of N1NED in $100 \mathrm{ml}$ of phosphoric acid 


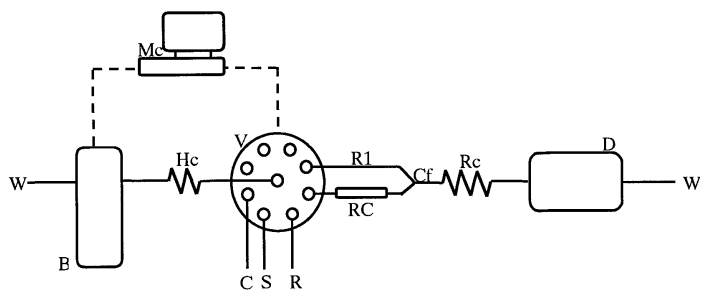

Fig. 1 SIA manifold used in the simultaneous determination of nitrite and nitrate in waters. S, sample; $\mathrm{C}$, carrier; $\mathrm{R}$, chromogenic reagent; $\mathrm{B}$, automatic burette; $\mathrm{V}$, valve; $\mathrm{D}$, detector; $\mathrm{Mc}$, microcomputer; Cf, confluence; Hc, holding coil; RC, copperized cadmium column; R1=160 cm; Rc, reaction coil $(100 \mathrm{~cm})$; W, waste.

(85\%) and $800 \mathrm{~cm}^{3}$ of water. The reagent was stored in a brown glass bottle in a refrigerator. The $\mathrm{pH}$ of this solution was adjusted to 2.0 with $\mathrm{NaOH}$ or $\mathrm{HCl}$.

A carrier solution was prepared by dissolving $0.4 \mathrm{~g}$ of EDTA $2 \mathrm{H}_{2} \mathrm{O}$ and $70 \mathrm{~g}$ of ammonium chloride in $1 \mathrm{dm}^{3}$ of water. The $\mathrm{pH}$ of this solution was adjusted to $9.0-9.5$ with a few drops of ammonia solution.

Copperized cadmium column was prepared by adding $5 \mathrm{~g}$ of cadmium particles (diameter between 0.5 and $1 \mathrm{~mm}$ ) to $50 \mathrm{~cm}^{3}$ of a copper(II) sulfate solution $(0.25 \mathrm{~g})$ and stirring for $2 \mathrm{~min}$. The resulting copperized cadmium was washed with $2 \mathrm{M}$ hydrochloric acid $\left(2 \times 50 \mathrm{~cm}^{3}\right)$ and ammonium chloride solution $\left(10 \mathrm{~g} \mathrm{dm}^{-3}\right)\left(2 \times 50 \mathrm{~cm}^{3}\right)$. The resulting particles were then packed into Teflon tube with $7-\mathrm{cm}$ of length and $1.5-\mathrm{mm}$ of inner diameter. ${ }^{18}$

The wastewater samples were collected at an wood industry site and correspond to the influent and effluent of the wastewater treatment plant.

\section{Equipment}

The sequential injection system used was composed of individual components. A CRISON microBU 2031 (Crison instruments, Alella, Spain) with a $5-\mathrm{mL}$ syringe was used as propulsor system. The solutions were propelled or aspirated at a constant flow-rate between $0.1-3 \mathrm{~cm}^{3} \mathrm{~min}^{-1}$.

A multiposition selection valve VICI (Valco Instruments Co. Inc.) with 8 inlets and 1 central outlet was used as injection system.

The manifold was built from PTFE tubing $(0.8 \mathrm{~mm}$ i.d.) with Gilson connectors. The confluence used was Perspex made.

A spectrophotometer UV/VIS JENWAY 6105, equipped with an $18-\mu \mathrm{L}$ flow-through cell of $1 \mathrm{~cm}$ path length was used for absorbance measurements at $543 \mathrm{~nm}$. The detector output was recorded on a Kipp \& Zonen recorder and signal evaluation was made by peak height measurements.

A microcomputer was used as control unity. All software was written in QuickBasic. The communication between microcomputer and burette was made by standard serial RS232C protocol, whereas digital TTL signals, using an Advantech Model 818 interface card was used for the connection with the valve. The same interface card was used for data acquisition.

\section{Conventional procedure}

The quality of the results obtained by the SIA system was assessed by comparison with those obtained by the reference method. Therefore, the procedures suggested by the "Standard Methods for the Examination of Water and Wastewater" 19 were applied.

\section{Results and Discussion}

The simple manifold used for the simultaneous determination of nitrite and nitrate by SIA is depicted in Fig. 1. The respective working parameters have been studied.

Once the optimal conditions of operation were established, the analytical features of the system have been determined and the quality of the results assessed.

\section{System optimization}

The analysis by the proposed system consists basically in the sequential aspiration of defined reagent and sample zones, which are adjacent to each other in a holding coil. After the valve has been moved to the detector position, the flow is reversed and the zones mutually disperse and merge in each other as they pass through a reaction coil towards the detector. For the simultaneous nitrite and nitrate determination with the developed system (Fig. 1), a measuring cycle comprised the following operations: in a first step, aspiration of carrier and introduction on the pathway to the detector, aspiration of sample and introduction in the reductor column, aspiration of reagent and introduction in R1. Sequentially, reagent from R1, sample from reductor column, reagent from $\mathrm{R} 1$ followed by carrier were introduced in the pathway to the detector. In a second step, aspiration of carrier, reagent, sample and reagent again to the holding coil and, by reversing the flow, introduction of this sequence in the pathway to the detector, followed by the carrier. The two reaction products formed during these two sequential procedures were detected spectrophotometrically and recorded. The first reaction product corresponded to the sum of nitrite and nitrate and the second was concerned only to nitrite.

In order to optimize the proposed SIA manifold, the influences of the hydrodynamic and chemical parameters on the magnitude of the peak height, reproducibility and accuracy of the results were studied. Experimental parameters were optimized by an univariate approach.

The concentrations of N1NED and sulfanilamide in phosphoric acid (85\%) that produce maximum analytical signals were 1 and $10 \mathrm{~g} \mathrm{dm}^{-3}$, respectively. The optimal results were obtained when the mixture of sulfanilamide and N1NED was used instead of separated solutions. The $\mathrm{pH}$ study showed that a value of 2.0 was the most appropriate for the reaction.

The optimum ammonium chloride concentration, in the carrier stream, was $70 \mathrm{~g} \mathrm{dm}^{-3}$; above this level, the response decreased because chloride ions inhibited the derivatization reaction and the reduction step, whereas below this level the response was erratic because of the decreased buffering capacity of the carrier stream. Values of $\mathrm{pH}$ of the carrier between 6.0 and $9.5 \mathrm{did}$ not demonstrate any effect in the nitrate reduction. A carrier solution with $\mathrm{pH} 9.0$ - 9.5 was used.

In the proposed system, the reduction efficiency was found to be very high using the prepared carrier solution containing EDTA/ $/ \mathrm{NH}_{4} \mathrm{Cl}(\mathrm{pH} 9.0$ - 9.5). It was important and necessary for maintaining the quantitative reduction that EDTA was involved in the carrier solution because the surface of $\mathrm{Cd} / \mathrm{Cu}$ particles was washed out by formation of a Cd-EDTA complex and an active surface could appear any time. ${ }^{20}$

The analytical signal was dependent on the changes of the length of the pathways to the detector. Lengths between 50 and $200 \mathrm{~cm}$ were tried, a decreasing in the analytical response being observed when longer pathways were used. A $100 \mathrm{~cm}$ pathway was chosen for further work.

Varying the flow rates, during the measurement step, over the range $0.5-3 \mathrm{~cm}^{3} \mathrm{~min}^{-1}$ did not produce any significant changes 
$\mathrm{H}$

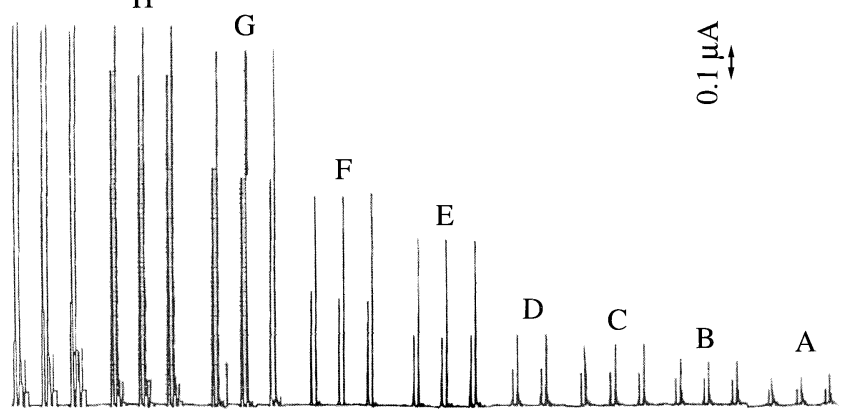

Fig. 2 Calibration record obtained for the different nitrite and nitrate standards. A, $0.05 \mathrm{mg} \mathrm{dm}^{-3} \mathrm{NO}_{2}^{-}+0.05 \mathrm{mg} \mathrm{dm}^{-3} \mathrm{NO}_{3}^{-} ; \mathrm{B}, 0.5$ $\mathrm{mg} \mathrm{dm}{ }^{-3} \mathrm{NO}_{2}^{-}+0.5 \mathrm{mg} \mathrm{dm}^{-3} \mathrm{NO}_{3}^{-} ; \mathrm{C}, 1 \mathrm{mg} \mathrm{dm}{ }^{-3} \mathrm{NO}_{2}^{-}+1 \mathrm{mg} \mathrm{dm}{ }^{-3}$ $\mathrm{NO}_{3}^{-} ; \mathrm{D}, 5 \mathrm{mg} \mathrm{dm}^{-3} \mathrm{NO}_{2}^{-}+5 \mathrm{mg} \mathrm{dm}^{-3} \mathrm{NO}_{3}^{-} ; \mathrm{E}, 10 \mathrm{mg} \mathrm{dm}^{-3} \mathrm{NO}_{2}^{-}+10$ $\mathrm{mg} \mathrm{dm}{ }^{-3} \mathrm{NO}_{3}^{-} ; \mathrm{F}, 15 \mathrm{mg} \mathrm{dm}^{-3} \mathrm{NO}_{2}^{-}+15 \mathrm{mg} \mathrm{dm}^{-3} \mathrm{NO}_{3}^{--} ; \mathrm{G}, 20 \mathrm{mg} \mathrm{dm}^{-3}$ $\mathrm{NO}_{2}^{-}+20 \mathrm{mg} \mathrm{dm}^{-3} \mathrm{NO}_{3}^{-} ; \mathrm{H}, 25 \mathrm{mg} \mathrm{dm}^{-3} \mathrm{NO}_{2}^{-}+25 \mathrm{mg} \mathrm{dm}^{-3} \mathrm{NO}_{3}^{-}$.

in the analytical signals. Additionally, the reduction of nitrate to nitrite was quantitative in the above range of flow rates. With flow rate above $3.0 \mathrm{~cm}^{3} \mathrm{~min}^{-1}$, a decrease of the analytical signal was observed, because of incomplete reduction. Hence, a flow rate of $2 \mathrm{~cm}^{3} \mathrm{~min}^{-1}$ was used, this being a compromise between the sampling rate and the height of the peak.

The effect of the length of the reductor column (1.5 mm i.d.) was examined with $4 \mathrm{~cm}, 6 \mathrm{~cm}, 8 \mathrm{~cm}$, and $10 \mathrm{~cm}$. Varying the length of the column showed that shorter columns give higher sensitivity because the sample is less dispersed, but longer columns obviously have a greater reducing capacity and therefore a longer lifetime. A 7-cm length and 1.5-mm inner diameter column was used for all further experiments.

For nitrate determination, the volume of sample introduced in the copperized cadmium column has a significant effect on the analytical signal. Precise and accurate results were obtained when $120 \mathrm{~mm}^{3}$ was used, because with this value the entire column was filled with sample and the dispersion was less. For nitrite determination, the signal increased with increasing sample volume in the range $10-500 \mathrm{~mm}^{3}$. A $120-\mathrm{mm}^{3}$ of sample was chosen for further work.

Furthermore, it was observed that the increase of the peak height and sensitivity of the measurements were better achieved by intercalating the sample in equal volumes of reagent. Hence, in nitrite and nitrate cases, each sample $\left(120 \mathrm{~mm}^{3}\right)$ was intercalated in $200+200 \mathrm{~mm}^{3}$ of reagent.

In Fig. 2, analytical signals obtained for the different standards of nitrite and nitrate, with concentrations between 0.05 and 25 $\mathrm{mg} \mathrm{dm}{ }^{-3}$ for both were presented. Two peaks were obtained for each standard; the bigger one was related to nitrite plus nitrate and the shorter one was related only to nitrite.

Calibration data obtained for the determination of nitrite in the range $0.05-25 \mathrm{mg} \mathrm{dm}^{-3}$ and for determination of nitrate in the range $0.05-15 \mathrm{mg} \mathrm{dm}^{-3}$ showed a linear relationship between concentration and analytical signal with correlation coefficients of 0.9994 and 0.9995 , respectively. The statistical limit of detection $(3 \sigma)$ was $0.01 \mathrm{mg} \mathrm{dm}^{-3}$ for nitrite and $0.01 \mathrm{mg} \mathrm{dm}^{-3}$ for nitrate. The precision of replicate injections was typically better than $2.0 \%$ for nitrite and better than $0.7 \%$ for nitrate. The sampling rate for both, because that was a simultaneous determination, was about 24 samples/h.

\section{Stability of the reductor column}

The copperized cadmium column is the critical component of
Table 1 Maximum tolerance levels of different interferent ions

\begin{tabular}{lcc}
\hline \multirow{2}{*}{ Ion added } & \multicolumn{2}{c}{ Tolerated concentration $/ \mathrm{mg} \mathrm{dm}^{-3}$} \\
\cline { 2 - 3 } & $\mathrm{NO}_{3}^{-}\left(0.5 \mathrm{mg} \mathrm{dm}^{-3}\right)$ & $\mathrm{NO}_{2}^{-}\left(0.5 \mathrm{~m} \mathrm{dm}^{-3}\right)$ \\
\hline $\mathrm{Na}^{+}$ & $1000^{\mathrm{a}}$ & $1000^{\mathrm{a}}$ \\
$\mathrm{K}^{+}$ & $1000^{\mathrm{a}}$ & $1000^{\mathrm{a}}$ \\
$\mathrm{Ca}^{2+}$ & 600 & 600 \\
$\mathrm{Mg}^{2+}$ & 400 & 400 \\
$\mathrm{Ni}^{2+}$ & 50 & 100 \\
$\mathrm{Fe}^{3+}$ & 50 & 50 \\
$\mathrm{NH}_{4}{ }^{+}$ & 100 & 150 \\
$\mathrm{Cl}^{-}$ & $1000^{\mathrm{a}}$ & $1000^{\mathrm{a}}$ \\
$\mathrm{C}_{2} \mathrm{O}_{4}{ }^{2-}$ & 100 & 100 \\
$\mathrm{SO}_{4}{ }^{2-}$ & 500 & 600 \\
$\mathrm{PO}_{4}{ }^{3-}$ & 10 & 150 \\
\hline
\end{tabular}

a. Maximum concentration tested.

the manifold with regard to unattended operating lifetime. Its long-term stability was examined in detail.

The lifetime of the column depended on the kind of samples analyzed. No problems were found when applied to the analysis of either standard solutions or natural waters and no need to replace the column or on-line regeneration for several months.

In the present work, the residence time of the sample in reductor was very short, only the necessary for the reduction reaction, and, on the other side, the column always stand filled with carrier between aspiration of different samples. By this way, active surface of the reductor was always present.

The lifetime of the reductor column used was found to be more than 3 months when regularly used. After this period, it was stored with EDTA/ $\mathrm{NH}_{4} \mathrm{Cl}$; approximately, one year later no significant decrease of reduction efficiency (less than $4 \%$ ) was observed.

\section{Interference study}

The potential interference of a certain number of ions in the nitrite and nitrate determination was examined by adding them to a standard solution containing $0.5 \mathrm{mg} \mathrm{dm}^{-3}$ of nitrite and to another standard solution containing $0.5 \mathrm{mg} \mathrm{dm}^{-3}$ of nitrate (Table 1).

A given ion was considered to interfere with the determination, if it resulted in a signal variation greater than two times the standard deviation.

In the nitrate determination, the main interference was that of phosphate, which caused an adverse effect even when present at $10 \mathrm{mg} \mathrm{dm}^{-3}$. The importance of the interference was found to be proportional to the concentration of phosphate in the sample and to the time of contact between this ion and the column. In the presence of oxidizing species, namely phosphate, the copper on the surface of copperized cadmium became uncoated. By this way, cadmium oxides or cadmium hydroxides formation appeared with consequent precipitation, resulting in a lost of activity of the reductor column. No decrease in the activity of the copperized reduction column was observed when a carrier solution containing EDTA was used in this system.

\section{Application to wastewater analysis}

The quality of the results obtained by the automatic system developed for the simultaneous determination of nitrite and nitrate in wastewaters was evaluated by comparing the results with those obtained by the reference method. ${ }^{19}$

A good agreement between the two methodologies was 
Table 2 Results obtained for ten wastewater samples, in the determination of nitrite and nitrate

\begin{tabular}{|c|c|c|c|c|c|c|}
\hline \multirow[b]{2}{*}{ Sample } & \multicolumn{3}{|c|}{$\mathrm{NO}_{2}^{-}$} & \multicolumn{3}{|c|}{$\mathrm{NO}_{3}^{-}$} \\
\hline & $\begin{array}{c}\mathrm{SIA}^{\mathrm{a}} / \\
\mathrm{mg} \mathrm{dm}^{-3}\end{array}$ & $\begin{array}{l}\text { Conventional method }{ }^{\mathrm{b}} / \\
\mathrm{mg} \mathrm{dm}^{-3}\end{array}$ & $\begin{array}{c}\text { Relative } \\
\text { deviation, \% }\end{array}$ & $\begin{array}{c}\mathrm{SIA}^{\mathrm{a}} / \\
\mathrm{mg} \mathrm{dm}^{-3}\end{array}$ & $\begin{array}{l}\text { Conventional method } / \mathrm{b} \\
\qquad \mathrm{mg} \mathrm{dm}^{-3}\end{array}$ & $\begin{array}{c}\text { Relative } \\
\text { deviation, \% }\end{array}$ \\
\hline 1 & $0.811 \pm 0.001$ & $0.84 \pm 0.01$ & -4.7 & $1.22 \pm 0.02$ & $1.27 \pm 0.02$ & -5.5 \\
\hline 2 & $0.502 \pm 0.004$ & $0.52 \pm 0.01$ & -4.7 & $1.61 \pm 0.02$ & $1.64 \pm 0.01$ & -2.4 \\
\hline 3 & $233 \pm 3$ & $228.2 \pm 0.5$ & 2.1 & $570.3 \pm 0.7$ & $575 \quad \pm 1$ & -0.8 \\
\hline 4 & $256.1 \pm 0.9$ & $259.1 \pm 0.2$ & -1.1 & $74.2 \pm 0.2$ & $71.2 \pm 0.2$ & 4.2 \\
\hline 5 & $0.513 \pm 0.001$ & $0.51 \pm 0.01$ & -1.9 & $1.05 \pm 0.01$ & $1.12 \pm 0.01$ & -9.0 \\
\hline 6 & $255 \quad \pm 3$ & $245.4 \pm 0.2$ & 4.0 & $47.2 \pm 0.3$ & $46.3 \pm 0.2$ & 2.1 \\
\hline 7 & 290 & $296.1 \pm 0.3$ & -2.0 & $482 \pm 3$ & $476 \pm 2$ & 1.2 \\
\hline 8 & $221 \pm 3$ & $220.3 \pm 0.3$ & 0.4 & 124 & 120 & 3.3 \\
\hline 9 & $194.3 \pm 0.6$ & $200.1 \pm 0.7$ & 3.0 & 104 & $109 \pm 1$ & -4.5 \\
\hline 10 & $206 \pm 2$ & $210.3 \pm 0.6$ & -1.9 & $114 \pm 2$ & $110.1 \pm 0.2$ & 3.6 \\
\hline
\end{tabular}

a. Mean and absolute deviation $(n=10)$ of each sample. b. Mean and absolute deviation $(n=3)$ of each sample.

obtained as shown by the linear relation with an intercept value near zero ( 0.060 for nitrite and 1.006 for nitrate), slope near unity ( 0.9978 for nitrite and 0.9985 for nitrate) and correlation coefficient close to one $(0.9982$ for nitrite and 0.9997 for nitrate).

Table 2 presents the results obtained using the two methodologies, for ten wastewater samples. The maximum relative deviation between the results attained by the developed system and by the conventional procedure was less than $2.0 \%$ for nitrite and $1.3 \%$ for nitrate.

\section{Conclusions}

The results obtained with the developed methodology applied to simultaneous monitoring of nitrite and nitrate in wastewaters show a good agreement with those obtained by the reference method. These results show that the methodology could be used as an advantageous alternative to the conventional methods.

The use of automated systems allowing on-line monitoring of different chemical species is of widely recognized importance for the analysis of environmental samples.

Small volumes of reagents and sample, which is important in continuous analysis as it means less maintenance and less disposal and, additionally, components and solutions clustered around the selection valve, thus facilitating the future minimisation of the system and its automatization what means computer-controlled operations running for extended periods, enable the system to operate in a variety of monitoring situations, such as water process control.

In the developed system, the desactivation of the column due to the presence of poisoning substances in the sample matrix was not observed when the EDTA/ $/ \mathrm{NH}_{4} \mathrm{Cl}$ solution was used for washing and storing the reductor column.

In conclusion, as the results show, the present system is reliable, economical, robust and labor-saving as compared with conventional methods and was proven to be useful in bioprocess monitoring.

\section{Acknowledgements}

The authors are grateful for the financial support through the
PRAXIS P/QUI/10035/1998 project. One of us (I.V.O.S. Pinto) thanks PRAXIS XXI program for the PhD grant (BD/9539/96).

\section{References}

1. W. E. Van der Linden, Anal. Chim. Acta, 1986, 179, 91.

2. S. C. Chung, G. D. Christian, and J. Ruzicka, Process Control and Quality, 1992, 3, 115.

3. M. T. Oms, A. Cerda, and V. Cerda, Anal. Chim. Acta, $\mathbf{1 9 9 5}, 315,321$.

4. J. Ruzicka and T. Gubeli, Anal. Chem., 1991, 63, 1680.

5. J. Ruzicka, Anal. Chim. Acta, 1992, 261, 3.

6. G. D. Christian and J. Ruzicka, Anal. Chim. Acta, 1992, $261,11$.

7. J. Ruzicka, Analyst, 1994, 119, 1925.

8. R. J. Burden, N. Z. J. Sci., 1982, 25, 205.

9. P. N. Magee, Ambio, 1977, 6, 123.

10. P. N. Magee, Phil. Trans. R. Soc. London, Ser. B, 1986 296, 543.

11. E. R. Jaffe, Clin. Hemat., 1981, 10, 99.

12. E. A. Walkers, Nitroso Compounds in the Environment, International Agency for Research on Cancer, Lêao, 1974, 80.

13. S. S. D. Foster, L. R. Bridge, A. K. Geake, A. R. Lawrence, and J. M. Parker, The Groundwater Nitrate Problem: A summary of research on the impact of agricultural land-use practices on ground-water quality between 1976 and 1985, 1986, Hydrogeol. Rep. Br. Geol. Survey, No. 86/2

14. H. Casey and R. T. Clarke, Freshwater Biol., 1979, 9, 91.

15. R. C. Hoather and R. F. Rackham, Analyst, 1959, 84, 548.

16. F. A. J. Armstrong, Anal. Chem., 1963, 35, 1292.

17. J. H. Wetters and K. L. Uglum, Anal. Chem., 1970, 42, 335.

18. N. J. Blundell, A. Hopkins, and P. J. Worsfold, J. Automatic Chem., 1993, 15(5), 159.

19. Standard Methods for the Examination of Water and Wastewater, 16th ed., 1985, American Public Health Association, Washington, D.C., Part 510.

20. K. Higuchi and S. Motomizu, Anal. Sci., 1999, 15, 129. 